\title{
COMPARISON BETWEEN THE MEAN POSTOPERATIVE PAIN SCORE WITH TWO DIFFERENT FILE SYSTEMS IN PATIENTS WITH IRREVERSIBLE PULPITIS-A CLINICAL STUDY IN ALTAMASH INSTITUTE OF DENTAL MEDICINE.
}

\author{
1. BDS \\ Department of Operative Dentistry \\ Altamash Institute of Dental \\ Medicine, Karachi. \\ 2. BDS, FCPS \\ Associate Professor and Head \\ Department of Operative Dentistry \\ Altamash Institute of Dental \\ Medicine, Karachi. \\ 3. BDS, FRDSC \\ Associate Professor and Head \\ Department of Oral Surgery/Maxilo \\ Facial \\ Altamash Institute of Dental \\ Medicine, Karachi. \\ 4. BDS \\ Department of Operative Dentistry \\ Altamash Institute of Dental \\ Medicine, Karachi. \\ 5. BDS \\ Department of Operative Dentistry \\ Altamash Institute of Dental \\ Medicine, Karachi.
}

Correspondence Address:

Dr. Sara Jamil

House \#:90/2/2,14TH Lane, Kh-e- Sehar, Phase 7, DHA, Karachi. drsara2222@gmail.com

Article received on:

06/10/2018

Accepted for publication:

15/05/2019

Received after proof reading:

$31 / 07 / 2019$

\section{INTRODUCTION}

Root canal treatment (RCT) is a common procedure in dentistry. When patient feels pain after RCT, and the treatment is below what patient is expecting is nowadays an important concern of dentists and a fear of patients as well. A recent systematic review shows, post-operative pain generally at 24 hours was $40 \%$ and was markedly decreased during the first 2days after adequate treatment done, and then dropping to $10 \%$ or less after 7 days. ${ }^{1}$ The International Associates for the Study of Pain (IASP) has defined pain as: a highly unpleasant physical and emotional sensation associated with actual or potential damage or described in terms of such damage. Flare-up is defined as a pain which arises in between the appointments of the treatment causing severe

\begin{abstract}
Sara Jamil' ${ }^{1}$, Rizwan Jouhar ${ }^{2}$, Dinaz Gandhi ${ }^{3}$, Tayyaba Tahira ${ }^{4}$, Jamshed Shaikh ${ }^{5}$ poor pathosis and a bad prognosis in long term, due to this a newer generation of instruments narrow and curved root canals, without causing aberration. To compare the mean postoperative pain score after manual SS (stainless steel) K-files and mechanical Ni-Ti rotary path files in patients with irreversible pulpitis. Study Design: Randomized controlled trial. Setting: Department of Operative Dentistry, Altamash Institute of Dental Medicine, Karachi. Period: 6 months from 01 moderate pain score $\geq 5$ were included and divided equally in manual stainless-steel k-files and mechanical Ni-Ti rotary path files groups. Treatment was started with local anesthesia. Patients were recalled after 24 hours and the level of postoperative pain was examined. T-test was applied to compare the outcome in both groups. Stratification was done using t-test and and and group-B was $2.33 \pm 1.02$ and $1.10 \pm 0.66$ respectively. A significant difference between the pre and post op pain was noted between the two groups, when compared after 24hours by using VAS. Conclusion: Mean post-operative pain score was significantly less with NiTi rotary
\end{abstract}

Ni-Ti Rotary Pathfiles, Irreversible Pulpitis. mean postoperative pain score with two different file systems in patients Medicine. Professional Med J 2019; 26(8):1359-1364.

DOI: 10.29309/TPMJ/2019.26.08.89

pain accompanied with swelling, which is actually caused by an intense pulpal or periradicular pathosis. $^{2}$ The development of postoperative pain after RCT is mainly when the infected debris from the canal is extruded outside the canal during chemo mechanical instrumentation, that causes an acute inflammatory reaction. ${ }^{3}$ Almost all techniques used to clean and shape the canal causes extrusion of debris from the apical terminus, the difference is mainly observed when various techniques and file systems are used which extrude less debris even when the working length is properly taken. Pre-treatment pain has a generally of $81 \%$ both for Visual Analog Scale (VAS) and category studies and Post-treatment pain generally at 24 hours is $40 \%$ decreasing to $11 \%$ at 1 week stated by Pasqualini et al. ${ }^{4}$ Pain originating 
from tooth after the root canal treatment after few hours or days is a poor indicator of pathosis and unreliable predictor of long-term success. Many Patients consider postoperative pain and flareup as a benchmark against which the dentist skills are measured. It might undermine patients' confidence in their dentists or patient satisfaction with the treatment. Although inter-appointment flare-up is uncommon, post-operative pain can still occur frequently even when the root canal treatment is adequately done, and it should be well informed to patients about this unpleasant occurrence. ${ }^{5}$

The paramount importance in the Success of endodontic therapy depends on the proper debridement of the canal system with cleaning and shaping being the major factor. Rests on the pedestal of the endodontic triad "diagnosis +anatomy + debridement = success", with proper debridement of the canal system with cleaning and shaping being of paramount importance in successful treatment. Coronalflaring is usually done by gates Glidden burs, the most dangerous and difficult phase, which should be done very carefully as most errors can be made during this phase, an entire treatment can fail if ledges, foramen transportations, dentine plugs are formed. Gates Glidden burs are relatively rigid and also involve numerous disadvantages, their tip is very aggressive and can cause perforations, and can also easily create ledges and transportation in curved and/ or calcified canals, so success in endodontic therapy rests on the endodontic triad "diagnosis + anatomy + debridement $=$ success". ${ }^{6}$

It is generally said that root canals can be adequately prepared when there is a reproducibility and sufficiently pathway to follow by the shaping canals. The glide path management is secret to shaping success, which is thought to be the most important factor for "securing" canals. A smallsized flexible hand file can secure any canal or any portion of the canal, it can reprint curve and calcified canals reproducibly slip, slide, and glide through a canal. ${ }^{7}$ The endodontic Glidepath is defined as a smooth root canal space from canal orifice to physiologic apical foramen. ${ }^{8}$
Newer generation of nickel titanium alloy endodontic instruments has been developed that potentially allows shaping of narrow, curved root canals, without any aberration. ${ }^{9}$ These instruments have super elastic behaviour and a shape memory effect. ${ }^{10}$

\section{MATERIAL AND METHODOLOGY}

Total 60 patients of irreversible pulpitis with moderate pain score $\geq 5$ were included and divided equally in manual SS K-files and mechanical NiTi rotary path files groups. Treatment was started with local anesthesia. Patients were recalled after 24 hours and the level of postoperative pain was examined. T-test was applied to compare the outcome in both groups. Stratification was done using $t$ test and $p$-value $\leq 0.05$ was considered as significant.

\section{RESULTS}

This study includes 60 patients of age between 20 years to 50 years of either gender meeting the inclusion criteria of study were included to compare the mean postoperative pain score after manual stainless-steel K-files and mechanical $\mathrm{Ni}-\mathrm{Ti}$ rotary path files in patients with irreversible pulpitis. In both study groups, Group A (canals prepared with Manual stainless-steel k-files) and Group B (canals prepared with mechanical Ni-Ti path files) 30 patients were Included.

The results showed $70 \%$ male and $86.7 \%$ female patients in group A while in Group B 30\% male and $13.3 \%$ female patients.

In both the groups the mean age was $33.40 \pm 9.67$ and $34.00 \pm 9.88$ years respectively.

The pretreatment mean VAS response of patients in group $A$ vs group $B$ was $7.16 \pm 1.44$ and $7.86 \pm 1.38$ respectively. The distributions of before and after treatment VAS response of both groups are presented in Figure-1,2,3 and 4 respectively. The descriptive statistics of pretreatment VAS response in both groups are presented in Table-I and Table-II.

In our study, mean post treatment VAS response in group-A vs group-B was $2.33 \pm 1.02$ and 
$1.10 \pm 0.66$ respectively.

In both groups, maxillary tooth was found as most common location.

Independent sample t-test was applied for the comparison of mean post treatment VAS score in two study groups. Results showed that there was a noticeable difference in mean post treatment VAS response between two study group $(p=0.000)$.

Stratification was done for gender, age and tooth location. Independent sample t-test was again applied to compare the mean post treatment VAS score in two study groups.

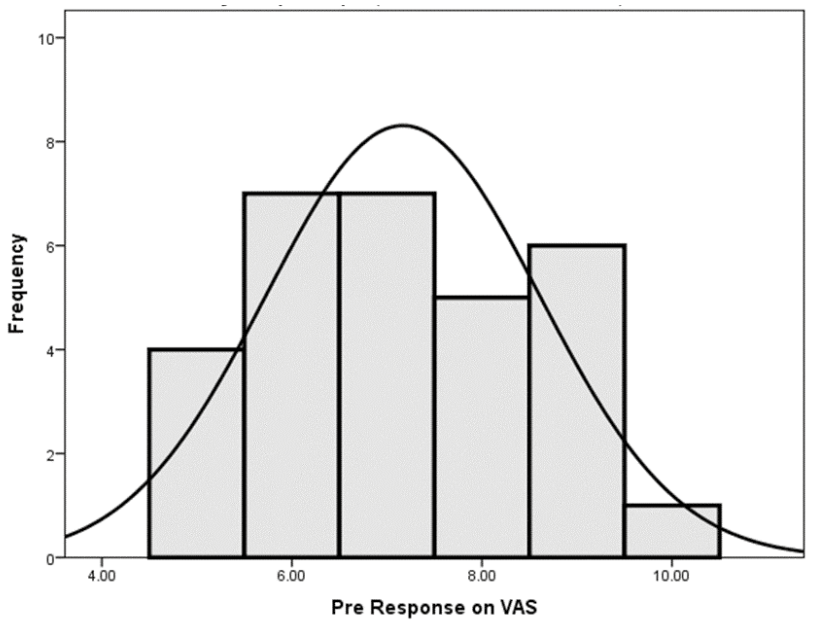

Figure-1. Histogram presentation of pre treatment VAS response in $(n=30)$ Group-A

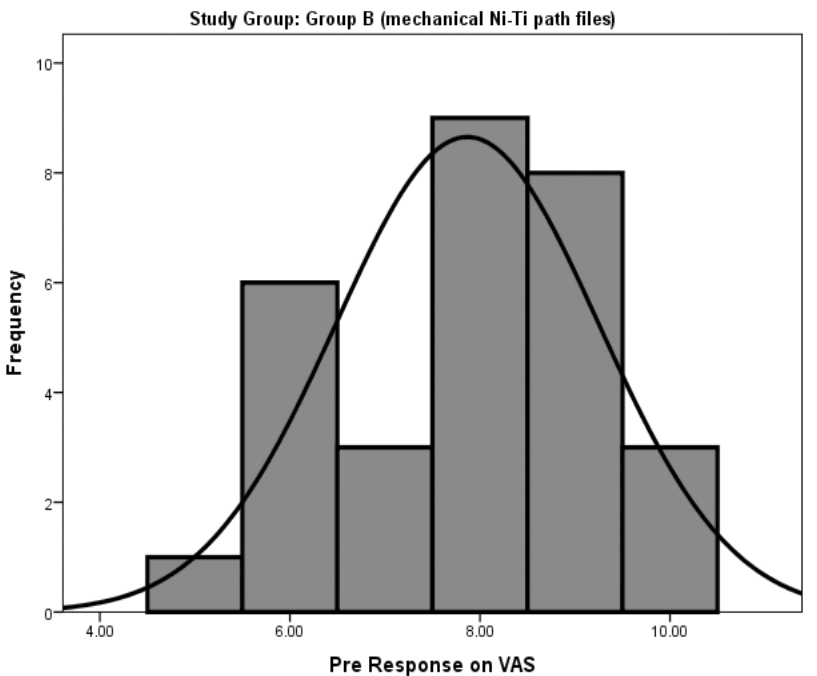

Figure-2. Histogram presentation of pre treatment VAS response in $(n=30)$ Group-B

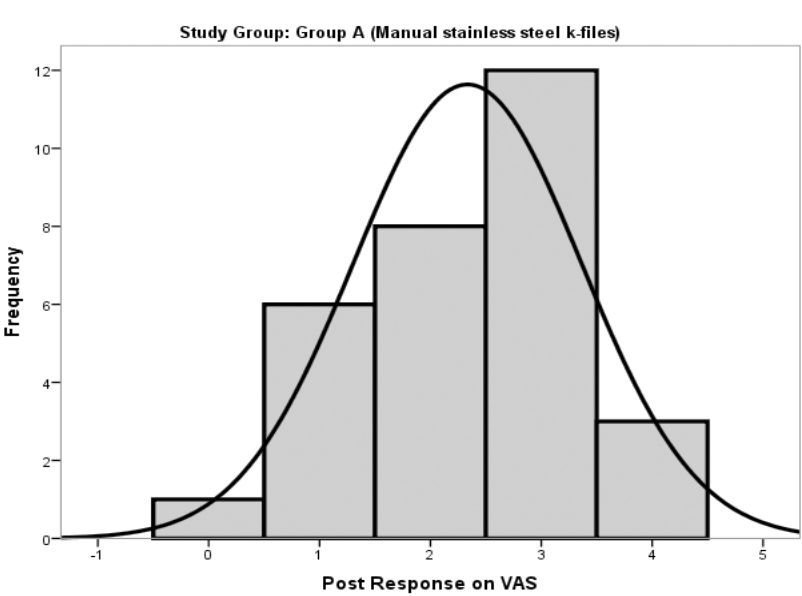

Figure-3. Histogram presentation of post treatment VAS response in $(n=30)$ Group-A

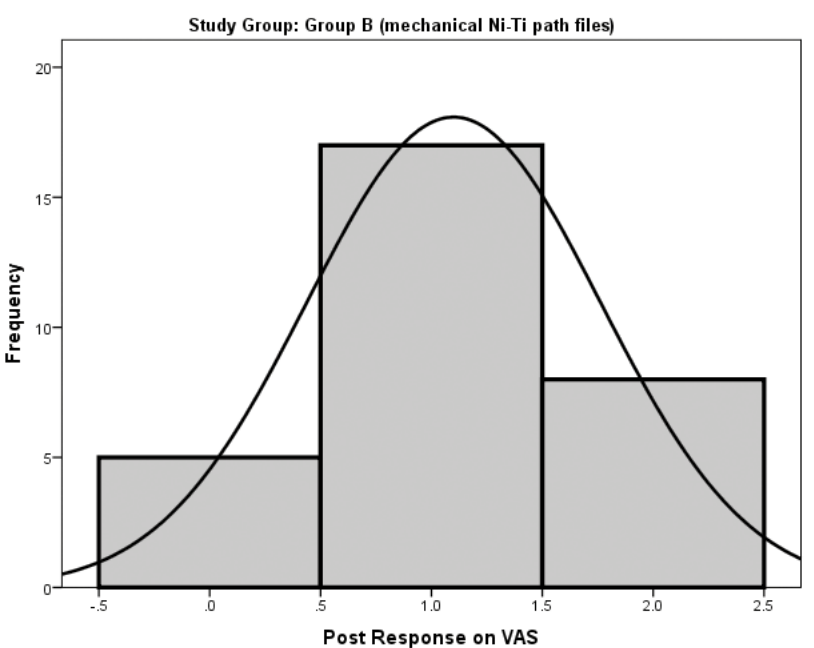

Figure-4. Histogram presentation of post treatment VAS response in $(n=30)$ Group-B

\section{Descriptive statistics of pre treatment VAS response in Group A $(n=30)$ \\ Mean $=7.16$}

$\mathrm{SD}=1.44$

Median $=7.00$

Minimum $=5$

Maximum $=10$

Range $=5$

\section{Descriptive statistics of post treatment VAS response in group $A$ $(n=30)$}

Mean $=2.33$

$\mathrm{SD}=1.02$

Median $=2.50$

Minimum $=0$

Maximum $=4$

Range $=4$
Descriptive statistics of pre treatment VAS response in Group B $(n=30)$ Mean $=7.86$ $\mathrm{SD}=1.38$ Median $=8.00$ Minimum $=5$ Maximum $=10$ Range $=5$

Descriptive statistics of post treatment VAS response in group $B$ $(n=30)$ Mean $=1.10$ $\mathrm{SD}=0.66$ Median $=1.00$ Minimum $=0$ Maximum $=2$ Range $=2$ 


\section{DISCUSSION}

If any injury to the pulp or especially periapical area occurs by means of mechanical, chemical or microbes are considered as the main causative factors of flare-ups. ${ }^{11}$

Researches previously done have shown different results according to post-operative pain incidences ranging from $1.4 \%$ to $16 \%$ and showed that sex, tooth number, tooth type, age of the patient, allergies, pulpal and periradicular status, pre-operative pain, the presence of a sinus tract, play a fundamental role. ${ }^{12}$

In our study we compared mean post treatment VAS after manual SS K-files and mechanical NiTi rotary path files in patients with irreversible pulpitis. On the basis of results of the present study, comparison of pain VAS between the two study groups showed significant differences. However, more pain VAS was detected in the hand file group after completion of the treatment. The subjective nature of postoperative pain is a source of difficulty in such studies, which depends on the cultural, individual and economic background of the subjects. Evaluation of pain is inherently difficult; therefore, in the present study the subjects received adequate explanations about postoperative VAS. Most subjects understand VAS technique easily and are able to rate their pain severity. VAS is considered a reliable and valid technique for evaluation of pain relief. In addition, all the technique- and operatorrelated variables were controlled since one single operator performed all the root canal therapy (RCT) procedures; the only differences were the file type and instrumentation technique in two separate groups.

The first phases of canal instrumentation includes canal scouting and preflaring. They are fundamental as it is safe for Ni-Ti rotary instruments because they ensure a root canal smoothened glide path with a larger or at least same diameter compared with non-cutting $\mathrm{Ni}-\mathrm{Ti}$ instruments tip diametre. ${ }^{13}$ Procedural complications and errors can be more frequently seen, and the extrusion amount of debris is also more at the preflaring phase. ${ }^{14} \mathrm{~A}$ newer generation $\mathrm{NiTi}$ rotary called as Path Files have been introduced by Dentsply Maillefer for mechanical pre-flaring. These files are less technique sensitive and less invasive. In simulated canals, it has been shown that clinicians' expertise do not play a significant role on shaping outcomes because both endodontic experienced as well as less experienced clinicians achieved similar results. ${ }^{15}$

The great feature elasticity of NiTi alloy increase the use of mechanical instruments for root canal shaping. ${ }^{16}$ The canal preparation was done more centrally with less chances of transportation and decrease occurrence of canal aberrations was seen by the pathfiles. ${ }^{17}$

Rotational Instrumentation techniques involves less extrusion of debris as compare to linear filing movement. ${ }^{18}$

However, the NiTi Rotary PFs have significantly showed better results. Despite the baseline conditions of diagnosis, tooth number, prevalence of pain, its extenstivity, postoperative pain curves and pain stop values in the PF group i.e Group B showed a more favorable condition in terms of relieving pain after time compared with the KF group i.e Group A. The mechanical instrumentation technique is mainly responsible for the debris amount which goes out from the apical foramen. ${ }^{19}$

In an in vitro study by Yeter et al., there were no significant differences in extrusion of debris between Revosystem rotary files and hand K-files. ${ }^{20}$ In another in vitro study, Vaudt et al., compared root canal preparation with two $\mathrm{NiTi}$ rotary systems (Alpha and Protaper Universal Systems) and SS hand files. Less debris was extruded with the use of the two rotary systems compared to hand K-files. ${ }^{21}$ Similar to an Iranian study, both aforementioned assessments used the crown-down technique to prepare the root canals in the rotary system groups and it was reported that use of the crown-down technique can decrease extrusion of debris from the root apex and the subsequent postoperative pain severity by enlarging the coronal third of the root canal and providing a path for the exit of debris 
from the root canals. ${ }^{22,23}$

\section{LIMITATIONS}

The few limitations of the study include a singlecenter experience and less female patients. The small sample size of this study does limit its applicability because it is not conducted in a generalized larger population and is conducted in a small urban environment.

\section{CONCLUSION}

NiTi rotary instruments such as Path files are highly beneficial to create a glide path, which in turn reduce post-operative pain, reduces the chances of transportation, ledges and flare ups. These qualities of this newer generation $\mathrm{NiTi}$ instruments has sufficiently greater influence on the individual quality of life. The results of the study concluded that mean post-operative pain score was significantly less with NiTi rotary path files as compare to manual stainless steel K-files. Copyright@ 15 May, 2019.

\section{REFERENCES}

1. Pak JG, White SN. Pain prevalence and severity before, during, and root canal treatment: A systematic review. J Endod. 2011; 37:429-38.

2. Iqbal M, Kurtz E, Kohli M. Incidence and factors related to flare-ups in a graduate endodontic programme. Int Endod J 2009; 42:99-104.

3. Sipavičiūtè E, Manelienè R, Stomatologija. Pain and fl are-up after endodontic treatment procedures. Baltic Dental Maxillofa J. 2014; 16:25-30.

4. Pasqualini D, Mollo L, Scotti N, Cantatore G, Castellucci $A$, Migliaretti $G$, et al. Postoperative pain after manual and mechanical glide path: $A$ randomized clinical trial. J Endod. 2012; 38(1):32-6.

5. Al-Zaka IM. The incidence of pain after root canal treatment using different irrigation methods. Tikrit JDental Sci. 2012; 1:38-43.

6. Berutti E, Cantatore G, Castellucci A. Use of nickel titanium rotary pathfile to create the glide path: Comparison With manual preflaring in simulated root canals. J Endod. 2009; 35(3):408-12.

7. Ruddle CJ, Machtou P, West JD. Endodontic canal preparation: Innovations in glide path management and shaping canals. Dent Today. 2014 Jul; 33(7):11823.
8. West JD. The endodontic Glidepath: "Secret to rotary safety". Dent Today. 2010 Sep; 29(9):86, 88,90-3.

9. Thompson SA, Dummer PM. Shaping ability of Mity Roto $\mathbf{3 6 0}$ degrees and Naviflex rotary nickel-titanium instruments in simulated root canals. Part 2. JEndod. 1998 Feb; 24(2):135-42.

10. Bramante CM, Betti LV. Comparative analysis of curved root canal preparation using nickel-titanium instruments with or without EDTA. J Endod. 2000May; 26(5):278-80.

11. Siqueira JF Jr. Microbial causes of endodontic flareups. Int Endod J 2003; 36: 453-63.

12. Rimmer $A$. The flare-up index: $A$ quantitative method to describe the phenomenon. J Endod. 1993; 19:2556.

13. Sonntag D, Guntermann A, Kim SK, Stachniss V. Root canal shaping with manual stainless steel files and rotary $\mathrm{Ni}-\mathrm{Ti}$ files performed by students. Int Endod $\mathrm{J}$ 2003; 36:246-55.

14. Bergmans L, Van Cleynenbreugel J, Wevers $M$, Lambrechts P. Mechanical root canal preparation with NiTi rotary instruments: rationale, performance and safety. Am J Dent. 2001 Oct;14(5):324-3.

15. Berutti E, Cantatore G, Castellucci A. Use of nickel titanium rotary pathfile to create the glide path: Comparison With manual preflaring in simulated root canals. J Endod. 2009; 35(3):408-12.

16. Coleman $\mathrm{CL}$, Svec TA. Analysis of $\mathrm{Ni}-\mathrm{Ti}$ versus stainless steel instrumentation in resin simulated canals. J Endod 1997; 23:232-5.

17. Kandaswamy D, Venkateshbabu N, Porkodi I, Pradeep G. Canal-centering ability: An endodontic challenge. J Conserv Dent 2009; 12:3-9.

18. Singla M, Aggarwal V, Logani A, Shah N. Comparative evaluation of rotary ProTaper, Profile, and conventional stepback technique on reduction in Enterococcus faecalis colony-forming units and vertical root fracture resistance of root canals. Oral Surgery, Oral Medicine, Oral Pathology, Oral Radiology, and Endodontology. 2010 Mar 1;109(3):e105-10.

19. Ng YL, Mann V, Gulabivala K. A prospective study of the factors affecting outcomes of nonsurgical root canal treatment: Part 1: periapical health. Int Endod J 2011; 44: 583-609. 
20. Yeter KY, Evcil MS, Ayranci LB, Ersoy I. Weight of apically extruded debris following use of two canal instrumentation techniques and two designs of irrigation needles. Int Endod J. 2013; 46(9):795-9.

21. Vaudt J, Bitter K, Neumann K, Kielbassa AM. Ex vivo study on root canal instrumentation of two rotary nickel-titanium systems in comparison to stainless steel hand instruments. Int Endod J 2009; 42:22-33.
22. Kandaswamy D, Venkateshbabu N, Porkodi I, Pradeep G. Canal-centering ability: An endodontic challenge. J Conserv Dent 2009; 12:3-9.

23. Fairbourn DR, McWalter GM, Montgomery S. The effect of four preparation techniques on the amount of apically extruded debris. J Endod 1987; 13:102-8.

\begin{tabular}{|c|l|l|l|}
\hline \multicolumn{2}{|c|}{ AUTHORSHIP AND CONTRIBUTION DECLARATION } \\
\hline Sr. \# & \multicolumn{1}{|c|}{ Author-s Full Name } & \multicolumn{1}{|c|}{ Contribution to the paper } & Author=s Signature \\
\hline 1 & Sara Jamil & $\begin{array}{l}\text { Clinical researches, Data } \\
\text { collector \& Correspondent. } \\
\text { Supervisor \& Data Analysis. }\end{array}$ \\
\hline 2 & Rizwan Jouhar & Droof reading. \\
\hline 4 & Tayyaba Tahira & Data collector. \\
\hline 5 & Jamshed Shaikh & Proof reading.
\end{tabular}

